\title{
Cinco desafíos para el abordaje de los (des)Bordes Urbanos
}

\section{Five challenges for the approach of (des) urban edges}

\author{
Salvador Schelotto*
}

Hábitat y Sociedad (ISSN 2173-125X), n. . 8, noviembre de 2015, pp. 5-12. * Coordinador de la Red temática
“(des) Bordes Urbanos”.
$\mathrm{E}$ 1 presente número de Hábitat y Sociedad está dedicado monográficamente a la temática de los desbordes urbanos, mediante la compilación de un conjunto de miradas y abordajes diversos relacionados con la problemática de los espacios periféricos de nuestras ciudades, los bordes y desbordes urbanos y específicamente desde la mirada de la sostenibilidad entendida de manera integral.

En consecuencia, el número que presentamos es producto de un acuerdo formal entre la Red temática "(des)Bordes Urbanos" del Programa iberoamericano CYTED (Ciencia y Tecnología para el Desarrollo) y la revista Hábitat y Sociedad: su temática y contenidos resultan del esfuerzo conjunto del equipo editorial de la revista y de algunos de los investigadores de los grupos participantes en la Red.

La Red “(des)Bordes Urbanos" inició sus actividades el 1 de enero de 2012 y culminará las mismas el 31 de diciembre de este año, al menos en lo que hace a su funcionamiento en el marco CYTED. Integra a diez grupos de investigación de seis países del ámbito iberoamericano (Argentina, Brasil, Chile, Ecuador, España y Uruguay) que pertenecen a universidades, cooperativas de profesionales, organizaciones internacionales y no gubernamentales. La riqueza y diversidad de su composición le ha permitido desplegar un variado conjunto de actividades en materia de investigación básica y aplicada, asesoramiento y transferencia a entidades de gobierno, universidades y organizaciones sociales, realizar publicaciones científicas y de divulgación, realizar cuatro seminarios internacionales y múltiples talleres, jornadas y cursos, a nivel de enseñanza de grado y de posgrado. Asimismo, le ha permitido celebrar por dos años consecutivos (2014 y 2015), la convocatoria al Concurso Internacional Desbordes Urbanos, que ha alcanzado una amplia respuesta, tanto en cantidad como en la calidad de los trabajos presentados y aceptados, y ha permitido premiar aquellos trabajos académicos, experiencias y trabajos de estudiantes que se distinguieron en relación al foco temático de sus trabajos.

A pesar de los avances registrados, cabe advertir que el concepto o la noción de "desborde urbano" sigue siendo, a casi cuatro años cumplidos del inicio de la actividad de la Red, una categoría en construcción.

Se trata de una aproximación a realidades complejas y cambiantes, que nos puede aportar mejores herramientas metodológicas y de comprensión de las mismas a la vez que ilustrar acerca de la forma de los territorios periféricos contemporáneos, pero por sobre todo acerca de las "formas de habitar" en los mismos. Y que nos puede referir, particular- 
mente, a las formas de producción social, apropiación y gestión de estos espacios.

Las periferias urbanas forman parte del universo de los "paisajes dialécticos" característicos de los procesos de urbanización contemporáneos, realidades poco conocidas y mucho menos comprendidas.

Pese a ello, las preocupaciones referidas precedentemente no son recientes: desde hace ya más de dos décadas quienes nos preocupamos por las ciudades y por su adecuada planificación y gestión, hemos dejado de considerar a las periferias urbanas como meros resultados, externalidades o residuos de los procesos urbanizadores acelerados o bien como una mera consecuencia, transitoria, del proceso de transición demográfica y urbanización de las poblaciones rurales.

Tampoco entendemos a los ámbitos periféricos como simples oportunidades para la implementación de promociones inmobiliarias y desarrollos especulativos, ni mucho menos como la "natural" posibilidad directa de expansión indiscriminada (continua o discontinua) de la mancha urbana, a costa de la pérdida del espacio rural (en otras palabras, las tendencias y vectores de expansión y dispersión residencial, y el crecimiento aparentemente sin fin).

Estas visiones y explicaciones, hegemónicas tiempo atrás, que responden a interpretaciones lineales de las dinámicas urbanas periféricas, están cuestionadas por la propia realidad.

En la actualidad, tanto las crecientemente densas y crecientemente consolidadas periferias urbanas como los anchos y variados espacios periurbanos constituyen verdaderas interfaces, interfaces complejas entre sistemas territoriales también complejos (que operan a modo de ecotonos entre sistemas ecológicos diversos): se trata de ámbitos capaces de ser vividos, de ser interpretados y ser entendidos como entidades con personalidad propia, que pueden ser explicadas e intervenidas desde el reconocimiento de sus especificidades en tanto espacios desarrollados históricamente con una lógica territorial propia.

Se trata, pues, de reconocer la existencia de ámbitos complejos, conflictivos, híbridos, que conforman fronteras vivas, cambiantes y móviles, que no solo registran una dinámica de expansión linealmente continua, sino que son el resultado de procesos que no responden a patrones predeterminados, algunos de los cuales implican pujos de contracción y transformación.

Espacios que usualmente forman parte de megaterritorios metropolitanos y de regiones urbanas. Que son organizados, surcados y complementados por grandes infraestructuras, redes de servicios, nodos logísticos y equipamientos.

En este sentido es en el que cabe poner en discusión su condición de "bordes" y apelar, para una mejor comprensión de su naturaleza, a la condición de "desbordes", entendida esta como una categoría conceptual en construcción, a la que es posible recurrir para obtener algunas explicaciones y, por sobre todo, de generar ciertas orientaciones para la acción.

En cierto modo, la idea tradicional de "borde" apela más a un desarrollo predominantemente lineal, definido, que opera a manera de límite o divisoria, física o visual, que no implica transiciones ni mediaciones, que se contrapone a un espesor de forma, ancho y densidad variable, como lo es un desborde.

Por lo tanto, esta mirada en construcción quiere ser un intento de comprensión de la realidad y a la vez de respuesta, un intento que confronta con la visión de las periferias urbanas como los espacios propios 
de la anomia social, de la precariedad urbano-habitacional, y como el mundo del liberalismo absoluto, en el que "todo vale", un lugar que se sitúa por fuera de las lógicas de lo que tradicionalmente se ha entendido como planificación y gestión urbana y territorial.

En algún caso, estas lógicas de crecimiento ilimitado han sido celebradas por académicos y formadores de opinión en estas áreas del conocimiento, a través de visualización de una suerte de "territorios líquidos" o posurbanos, empleando conceptos análogos a los usados para proyectar ciertas miradas sobre la realidad social desde la modernidad contemporánea en el marco de cierto tipo de "pensamiento débil".

Lo cierto es que las intervenciones a realizar en estos territorios requieren de la construcción sistemática de una mirada específica. Intentando construir el circuito de reunir información y hacerlo de manera acumulativa y sistemática, interpretar dicha información y explicar la realidad construyendo un nuevo relato, proponerse transformar esa realidad a través de una operación proyectual y finalmente intervenir en la misma, retroalimentando esa intervención con la evaluación y el monitoreo de los resultados.

Fernando Carrión, entre otros, hace algunos años, postuló la idea del "derecho al centro", que hoy puede ser vista tanto como una visión anticipatoria como una consigna provocadora y que en su momento fue generadora de nuevas miradas sobre los centros históricos y sobre las centralidades en general.

Por extensión y analogía, podríamos sostener hoy el "derecho al borde urbano", entendido como un ámbito periférico caracterizado, conformado, integrado, calificado; un ambiente y un hábitat en el que sea posible vivir bien, convivir y trabajar. Ámbito a dotar de un cabal sentido de lugar y de la adecuada accesibilidad a los bienes y servicios propios de la urbanidad contemporánea.

Múltiples experiencias, a lo largo y ancho de América Latina y en el espacio cultural iberoamericano, fundamentalmente dirigidas desde los Gobiernos locales o los Gobiernos de ciudad, están avanzando en direcciones similares; cuentan con objetivos análogos y se concretan a través de formas de dotación de recursos y sistemas de implementación y gestión bien diferentes. Desde la experiencia de los Proyectos Urbanos Integrales de la ciudad de Medellín en Colombia, hasta los procesos de intervención y urbanización en favelas en ciudades de Brasil.

Programas públicos diversos, dirigidos específicamente a las áreas de riesgo y vulnerabilidad, se deben integrar en el abordaje del tejido urbano precarizado y de las situaciones de precariedad dispersa con el conjunto de los demás programas de rehabilitación y conservación de stock construido y a la vez con la cuestión del nuevo abordaje del tema del espacio público, en particular de los "nuevos" espacios públicos como lo son las plazas integradoras, plazas de convivencia, equipamientos públicos, escuelas.

Por otra parte, y con una mirada estructural, consideramos que es necesario enfatizar que la planificación, el proyecto y el desarrollo de las infraestructuras y el aseguramiento del acceso a los servicios, se complementa con el necesario "sentido" que deben adquirir los espacios periféricos o de interfase, la adquisición de su carácter de ciudad, su definitiva urbanidad, superando los tradicionales y engañosos imaginarios suburbanos genéricos.

En Iberoamérica hemos aprendido que el incremento de la renta y los ingresos de las personas y de las familias, y el aumento del consumo privado, no asegura de por sí la mejora de las condiciones de vida. 
Y que tampoco la producción masiva de nuevas unidades de vivienda resuelve los problemas del hábitat y la inclusión social, generando ambientes urbanos y territorios sostenibles e integrados (muchas veces ocurre lo contrario).

Por esa razón, es necesario plantearse permanentemente nuevas preguntas. Las respuestas a estas interrogantes deberán emerger de miradas más complejas y transversales.

El tema del acceso al suelo urbanizado, el tema de la permanencia y el arraigo, el tema de no ghettización de las comunidades periféricas y la lucha contra la segregación socioespacial, la discusión sobre las formas de participación de la población y en particular de los usuarios en la construcción social del hábitat son cuestiones que forman parte de esta agenda.

Por lo pronto, la exigencia es intervenir no solamente a escala de la unidad de vivienda o el conjunto habitacional, sino a la escala de barrio o parte de ciudad, integrando el espacio habitacional, el comercial, el productivo y de servicios, con el espacio público.

Y también es necesario introducir en el debate, en la agenda de temas prioritarios y en la consideración de la complejidad de estos territorios, cuestiones vinculadas a la articulación económica a escala ciudad, a escala país y a escala global, esto es, el entendimiento del espacio periférico como lugar para localización de actividades económicas potentes; como "suelo" o mero soporte, capaz de admitir nuevos usos, considerando además sus impactos en el paisaje y en las formas tradicionales de ocupación y uso del territorio periurbano, en la agricultura familiar, en la huerta, en el espacio recreativo y en las áreas naturales de valor ecosistémico.

$\mathrm{Si}$ entendemos que las ciudades emergen y se desarrollan como organizaciones para la vida colectiva, y sin desconocer que ellas contienen al conflicto y se explican por las contradicciones sociales, las políticas de vivienda y hábitat deben integrar, desde el reconocimiento y la asunción del conflicto y de la diversidad de intereses, una mirada comprensiva del todo y reconocedora de sus partes.

Pero, por otra parte, el derecho a la ciudad, como señala David Harvey, es un derecho colectivo, esto es, un derecho del conjunto los ciudadanos como tales, aun en sociedades desiguales.

La ciudad, una y múltiple a la vez, como reiteradamente nos enseñaba Mariano Arana, está continuamente sometida a las tensiones de las apetencias del mercado, las regulaciones estatales, las prácticas sociales y culturales, las miradas desde el pensamiento crítico y las expresiones políticas.

La idea de "monumentalización de las periferias" postulada hace ya mucho tiempo por Oriol Bohigas, es una mirada hoy lejana de nuestras realidades, pero que se mantiene vigente como aspiración de dotar de un sentido de lugar a estos espacios de transición, que frecuentemente están desestructurados y faltos de cualidades urbanas.

El derecho al borde urbano, en sus diversas manifestaciones físicas y culturales, es un derecho tanto de los habitantes del mundo de las periferias como de quienes participan del conjunto de la ciudad.

La definición de potentes centralidades periféricas — valga la aparente contradicción al usar este término- que superen las dotaciones de equipamientos para el consumo, la producción o la distribución y que integren los espacios calificados para la educación, la convivencia, el intercambio, el disfrute cultural, el ocio y el deporte, entre otros, signados por referencias identitarias que horaden las imágenes de "ciu- 
dad genérica” como la que describe Rem Koolhas, para así afirmar los valores de lo local.

En cierto modo, se nos plantea una perspectiva de contraposición entre la ciudad compacta, densa en interacciones y para todos, y el sprawl urbano -insustentable - que tensa y a la vez presiona los límites de la planificación urbana y el ordenamiento territorial.

Apostamos a que es posible gestionar e implementar modelos urbanos policéntricos, insertos en espacios metropolitanos complejos, heterogéneamente discontinuos, que alternen espacios de suelo urbano, periurbano y rural con identidades concretas y específicas, que se manifiestan en paisajes caracterizados.

En el entramado de esas líneas de fuerza, emerge la vivienda como elemento conformador de lo urbano, con densidades, tipologías y morfologías adecuadas.

La vivienda social en este marco deberá ser entendida como un repertorio de respuestas específicas, adecuadas, de calidad, que generan urbanidad. Que promueve la mayor heterogeneidad, a la escala de barrio, con diversidades de arreglos familiares, etáreas y generacionales, de franjas de ingresos, con variadas de formas de acceso al suelo y a la vivienda $\mathrm{y}$ variadas formas de tenencia de la misma (en propiedad, en alquiler, en usufructo) y por medio de diversos mecanismos que la viabilizan (construcción en diversas modalidades, refacción y rehabilitación, adquisición de vivienda usada, etc.). Instrumentos, participantes y modalidades que deben operar en cierto modo como "trajes a medida", acciones diseñadas para abordar y resolver algunos de los problemas más complejos y más postergados, en las escalas adecuadas para la intervención.

Nos seguimos preguntando, en términos de vivienda y hábitat, cómo se podrá materializar el Derecho a la ciudad: cómo integrar la prioridad de las políticas públicas para con los más vulnerables en el contexto del interés público o interés general, y cómo se concreta la aspiración de universalidad de estos derechos colectivos, postulados hace ya tiempo y aún pendientes de garantizar.

Por todo lo anterior, es posible resumir que la problemática planteada implica, al menos, cinco grandes desafíos para el abordaje de los (des) Bordes Urbanos: conocer la realidad, interpretarla, planificar. Intervenir en ella y evaluar lo hecho.

1. Conocer la realidad de nuestras periferias urbanas. Este desafío implica desarrollar tanto operaciones de construcción teórico conceptual y definición de pautas operativas; así como de la crítica de paradigmas urbanos preexistentes, procurando conformar nuevos marcos interpretativos capaces de dar cuenta de los procesos contemporáneos.

2. Interpretar esa realidad. Este desafío hace a la necesidad de generar nuevos relatos sobre los espacios periféricos. Decodificar los datos, jerarquizarlos y encontrar aquellos aspectos clave que permitan hilvanar un nuevo discurso. Un discurso que comunique e informe.

3. Planificar. La idea de planificación necesariamente es asociada con frecuencia a la rigidez y el formalismo. Nada más alejado de la inspiración última de los procesos planificadores: es necesario generar planificaciones flexibles, adaptativas, participativas y eficaces para resolver problemas y más aún, anticiparse a ellos.

4. Intervenir en la transformación. La planificación sin la acción es un esfuerzo trunco y estéril. La actuación en los procesos dinámicos 
de transformación de los ámbitos urbanos periféricos necesariamente es multiactoral y multinivel, implica transversalmente a las administraciones y requiere de la participación social.

5. Evaluar y monitorear, aprender. Por último, tenemos el desafío de aprender de lo hecho y de lo no hecho, de los logros y los fracasos. Evaluar de manera rigurosa, monitorear los procesos y sacar conclusiones, de manera de que se logre un circuito virtuoso de aprendizaje social, condición imprescindible de la sostenibilidad.

Los contenidos de este número monográfico avanzan en este camino, desde puntos de vista y preocupaciones bien diversas, pero claramente convergentes:

- José María López plantea un aporte fundamental en cuanto a la conceptualización de la noción de "desbordes". Desde su artículo "Des-Bordes urbanos: un concepto en construcción" nos introduce con profundidad en el debate urbano contemporáneo y pone el foco en el concepto "en construcción" que se procura atrapar.

- Pedro Lorenzo, a su vez, se aproxima a su realización desde la propuesta de una metodología de análisis y modalidades de intervención. En su artículo "Influencia de la ESCALA de decisión e intervención en el proceso de mejora y producción social del hábitat (La gestión y el control social de la ciudad)" profundiza en el concepto de desborde urbano como primera referencia de la transformación de la dimensión de la ciudad, concretándose en la evolución de las periferias donde la posesión del suelo es un gran campo de acción de las dos maneras de ocupar el espacio: conseguirlo para vivir o edificarlo para vender. Y sabiendo que este no es el único lugar donde se producen los desbordes no solo físicos, sino sociales, económicos y culturales en la ciudad.

- Rafael Balanzó nos propone el primer estudio de caso: presenta el proceso del barrio de Vallcarca, en la ciudad de Barcelona, en tanto es un ejemplo elocuente de la evolución de la resiliencia en las dinámicas de las prácticas urbanísticas, a partir de una visión sistémica, evolutiva y multiescalar, utilizada para el estudio de los sistemas socioecológicos.

- Por su parte, Paola Bagnera y Belén Penissi también plantean un estudio de caso de no menor interés: nos acercan el trabajo "La vivienda y la sustentabilidad en la Riviera Maya: los desbordes del turismo", encarando un ejemplo representativo de la cuestión de los territorios turísticos en América Latina y los riesgos de insustentabilidad que presentan.

- A su vez, Carlos Felipe Urazán Bonells y Francesc Magrinyá Torner también abordan un caso concreto en el artículo "El rol de los servicios urbanos en la legalización predial y la generación de calidad urbana y valor del suelo. Aplicación al caso de Cúcuta (Colombia)", en el que analizan y presentan la interrelación entre la legalización predial, la mejora de los servicios urbanos y la mejora de la vivienda.

- Por último, Vicente Manzano-Arrondo y Enrique Suárez García incursionan en la cuestión del compromiso social de la Universidad, desde una mirada usualmente soslayada de la práctica universitaria de nuestro tiempo: su trabajo "Unidad de acción comprometida: una propuesta de solución ante el problema uni- 
versitario del servicio a la sociedad" plantea una agenda de integración de las funciones universitarias fundamentales: docencia, investigación y extensión, que han venido sufriendo problemas de desajuste y desequilibrio.

- Finalmente, en el espacio LED, Rafael Fuentes-Guerra Soldevilla, Isabel Toral López, Araceli Martín Fuentes y Manuel Martínez Cuevas nos comunican una experiencia en curso de implementación, que reviste un interés particular: "Alimentación Responsable en la Escuela Pública. Una experiencia de eco-comedor autogestionado (CEIP “Gómez Moreno”. Albayzín. Granada)”.

Como comentario final, diremos que desde nuestra Red estamos convencidos de que el material que este número monográfico ha reunido no solamente contiene interesantes contribuciones originales, de valor científico, sino que además las mismas presentan una contundente pertinencia temática y metodológica para el desarrollo de prácticas transformadoras de la realidad.

Agradecemos, pues, a la revista Hábitat y Sociedad por habernos permitido compartir el espacio de análisis y reflexión que hemos construido conjuntamente y la posibilidad de divulgación que ello supone.

Estamos convencidos de que se trata de un paso significativo en la dirección de generar, en forma compartida, nuevas miradas, transversales, innovadoras e integrales, tan reclamadas como ausentes en la urgencia de la praxis.

SCHELOTTO, Salvador. Cinco desafíos para el abordaje de los (des)Bordes Urbanos. Hábitat y Sociedad, 2015, n. ${ }^{\circ}$ 8, pp. 5-12.

$<$ www.habitatysociedad.us.es >

http://dx.doi.org/10.12795/HabitatySociedad.2015.i8.01

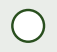

